\title{
Internal carotid artery occlusion should not exclude surgery
}

Maciej Gaciong, Agnieszka Pisarek, Krzysztof Bojakowski

Department of General and Vascular Surgery, Central Clinical Hospital, Ministry of Interior, Warsaw, Poland

Submitted: 14 June 2016

Accepted: 10 July 2016

Arch Med Sci Atheroscler Dis 2016; 1: e75-e77

DOI: 10.5114/amsad.2016.61495

Copyright $\odot 2016$ Termedia \& Banach

Recent guidelines do not recommend revascularization of chronic internal carotid artery (ICA) occlusion [1]. However, patients with ICA occlusion have real risk of a new stroke, and in a retrospective, population-based study of symptomatic ICA occlusion, prevalence of cerebral infarction during follow-up was $8 \%$ at 30 days, $10 \%$ at 1 year, and $14 \%$ at 5 years [2]. This article describes a case of a symptomatic patient with ICA occlusion who underwent successful carotid endarterectomy (CEA) with resolution of symptoms and an uneventful clinical course in the following 2 years.

A 62-year-old man was admitted to the neurological department because of episodes of amaurosis fugax in the left eye. The patient had a history of hypertension, type 2 diabetes, smoking and benign prostatic hyperplasia. Multi-slice computed tomography (CT) angiography revealed short occlusion of the left ICA bulb (Figure 1 A), and baseline CT showed mild hypodensity of cerebral white matter of the parietal lobes, more severe on the left side, described as characteristic for insufficient cerebral circulation. The patient was initially qualified for medical treatment (aspirin, statin). Because of repeated recurrence of neurological symptoms, color duplex carotid ultrasonography was performed. It showed a short $<20 \mathrm{~mm}$ segment with atherosclerotic plaque causing high-grade stenosis or occlusion in the proximal segment of the left ICA and a possible patent lumen in the distal cervical part. The patient was qualified for left carotid endarterectomy. Surgery was performed with regional anesthesia and brain function was monitored by the level of consciousness and motor activity in the upper limb on the contralateral side of the body. There were no symptoms of cerebral ischemia that would have required placement of a carotid shunt. During surgery, occlusion of a short (15-20 mm) segment of the left ICA was found. Also, a small artery (outer diameter around $1 \mathrm{~mm}$ ) originating from the posterior wall of the ICA, above the occluded segment, was detected. The atheromatous plaque was removed and the ICA was closed with a carotid patch. The postoperative course was uneventful, and the patient was discharged on the second postoperative day. During the follow-up period no episodes of amaurosis fugax or other neurological symptoms occurred. Ultrasonography and CT angiography performed 6 months after surgery revealed a patent left ICA (Figure $1 \mathrm{~B}$ ). The patient had no neurological symptoms during 2 years of follow-up.

Although asymptomatic ICA occlusion is considered to have a relatively benign course, symptomatic occlusion increases future risk of stroke.

\author{
Corresponding author: \\ Maciej Gaciong MD \\ Department of General \\ and Vascular Surgery \\ Central Clinical Hospital \\ Ministry of Interior \\ 137 Wołoska St \\ 02-507 Warsaw, Poland \\ Phone: +48516088 835 \\ Fax: +48225991828 \\ E-mail: maciej.gaciong@ \\ gmail.com
}



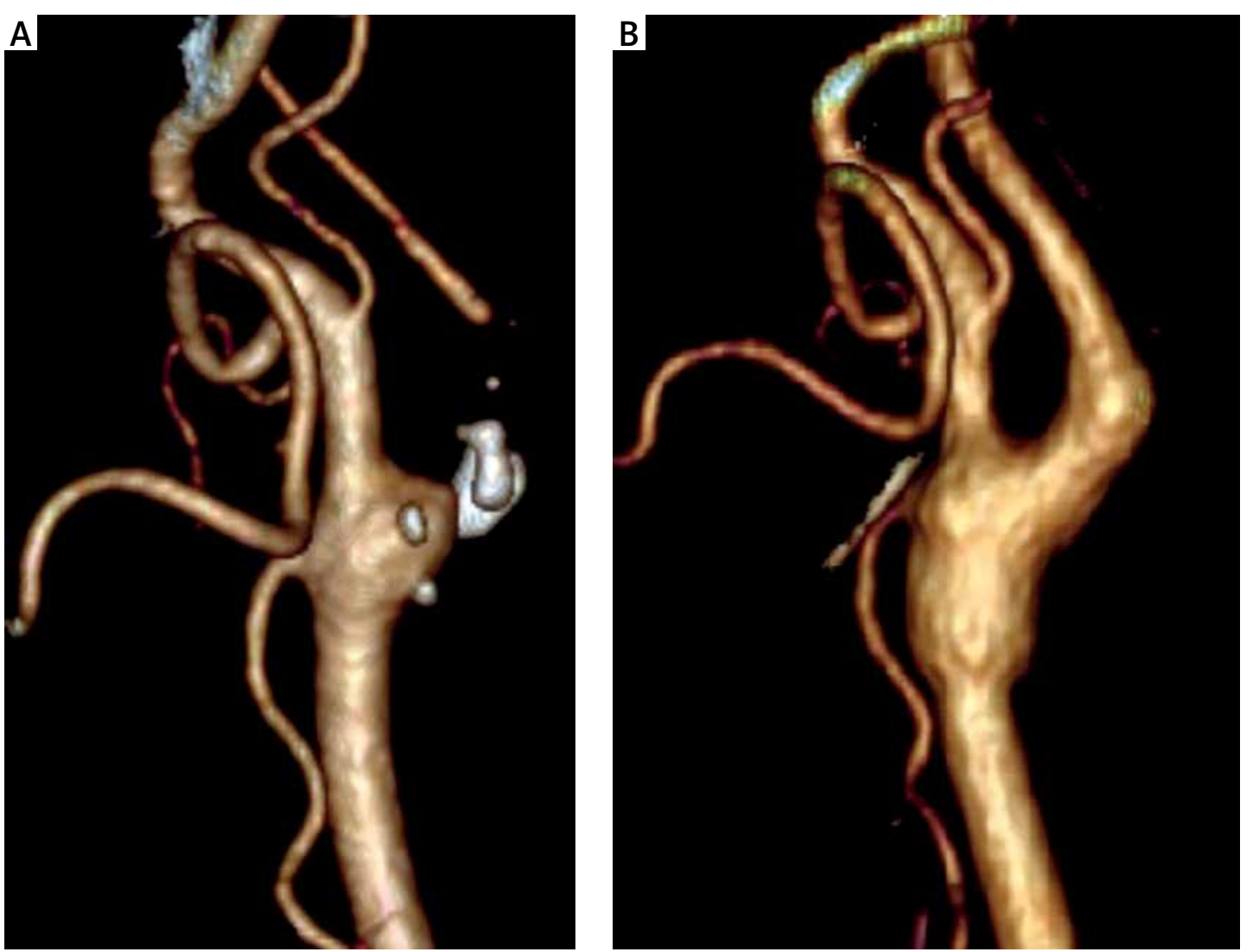

Figure 1. A - Calcifications in the bulb and occlusion of the left internal carotid artery. Narrow $2 \mathrm{~mm}$ flow reappears above the bulb. B - Patent left internal carotid artery 6 months after the procedure

According to the results of Powers et al., ischemic stroke occurred in 1 (3.3\%) of 30 never-symptomatic patients and in 15 (18.5\%) of 81 symptomatic patients [3]. Other studies show annual stroke rates as high as $20 \%$ at the time of occlusion to approximately $5-10 \%$ after 1 year.

There are several mechanisms potentially contributing to post-occlusion ischemic events. It has been hypothesized that these episodes are caused by embolism either from the stump or from atherosclerotic plaques in the common or external carotid artery, which can be carried through the collateral pathways to the ipsilateral hemisphere or retina. In addition, it has been shown that some embolisms can form on the distal tail of the occluded ICA. Embolism probably accounts for almost $2 / 3$ strokes in patients with ICA occlusion $[2,4]$.

Normally, the ICA has no branches in the neck, so in case of typical total occlusion, the whole cervical segment to the first intracranial patent branch is blocked. However, as observed in the case of our patient, different anatomical variants of the ICA and its collaterals can be found. Atypical branches of the ICA were detected in fewer than $1 \%$ of subjects. These additional branches create potential alternative routes for embolic material, and the possibility of their presence should be considered in patients with an occluded ICA $[5,6]$.
There is also a possibility of pseudo-occlusion with minimal flow undetected during imaging studies.

Rarely, spontaneous revascularization can occur due to the formation of a vascular network between the atherosclerotic plaque and the vasa vasorum. These new collaterals can be a new route of stroke-triggering unstable atherosclerotic plaque debris [7]. Ischemic symptoms after ICA occlusion may result from compromised cerebral blood flow due to insufficient perfusion via the circle of Willis, the ophthalmic artery or the leptomeningeal collaterals.

During the past decades, occluded carotid arteries were treated surgically with CEA or bypass anastomosis. These studies mostly include patients with acute occlusion of the ICA and reported minor clinical benefits despite a high patency rate $[8,9]$.

There are also reports of single cases or small series of patients who underwent successful endovascular revascularization of an occluded ICA. In a group of 8 patients with symptomatic ICA occlusions (mean duration: 2.5 months) angioplasty and stenting was successful in 7 of 8 patients. There were no periprocedural complications, and improvement of ipsilateral cerebral hemodynamics was observed. However, asymptomatic minor strokes were found on an magnetic resonance imaging (MRI) scan in 6 out of 8 patients [10]. 
In conclusion, patients with total ICA occlusion remain at increased risk of cerebrovascular incidents. In our opinion, it is possible to select a group of patients with ICA occlusion, who would benefit from surgical revascularization. Especially, symptomatic subjects with a short occluded segment of the ICA, with a patent distal cervical part of the artery, can be managed by bypass or CEA. Examination with multi-slice CT angiography or angiography is necessary for evaluation of the morphology of the occluded segment and the presence of rare anatomical variants of ICA branches and collaterals. Measurement of cerebrovascular reserve using transcranial Doppler and MRI could identify asymptomatic patients who are at greater risk of stroke due to cerebral hypoperfusion or embolism.

\section{Conflict of interest}

The authors declare no conflict of interest.

\section{References}

1. Brott TG, Halperin JL, Abbara S, et al. 2011 ASA/ACCF/ AHA/AANN/AANS/ACR/ASNR/CNS/SAIP/SCAI/SIR/SNIS/ SVM/SVS Guideline on the Management of Patients With Extracranial Carotid and Vertebral Artery Disease A Report of the American College of Cardiology Foundation/American Heart Association Task Force on Practice Guidelines, and the American Stroke Association, American Association of Neuroscience Nurses, American Association of Neurological Surgeons, American College of Radiology, American Society of Neuroradiology, Congress of Neurological Surgeons, Society of Atherosclerosis Imaging and Prevention, Society for Cardiovascular Angiography and Interventions, Society of Interventional Radiology, Society of Neurolnterventional Surgery, Society for Vascular Medicine, and Society for Vascular Surgery. Circulation 2011; 124: e54-130.

2. Flaherty ML, Flemming KD, McClelland R, et al. Population-based study of symptomatic internal carotid artery occlusion: incidence and long-term follow-up. Stroke 2004; 35: e349-52.

3. Powers WJ, Derdeyn CP, Fritsch SM, et al. Benign prognosis of never-symptomatic carotid occlusion. Neurology 2000; 54: 878-82.

4. Bryan DS, Carson J, Hall $\mathrm{H}$, et al. Natural history of carotid artery occlusion. Ann Vasc Surg 2013; 27: 186-93.

5. Makowicz G, Poniatowska R, Lusawa M. Variants of cerebral arteries - anterior circulation. Pol J Radiol 2013; 78: 42-7.

6. Luh GY, Dean BL, Tomsick TA, et al. The persistent fetal carotid-vertebrobasilar anastomoses. AJR Am J Roentgenol 1999; 172: 1427-32.

7. Meguro T, Muraoka K, Terada K, et al. Recanalisation of the internal carotid artery via the vasa vasorum after coil occlusion. Br J Radiol 2011; 84: e23-6.

8. Weis-Müller BT, Huber R, Spivak-Dats A, et al. Symptomatic acute occlusion of the internal carotid artery: reappraisal of urgent vascular reconstruction based on current stroke imaging. J Vasc Surg 2008; 47: 752-9.

9. Mokin M, Kass-Hout T, Kass-Hout O, et al. Intravenous thrombolysis and endovascular therapy for acute ischemic stroke with internal carotid artery occlusion: a sys- tematic review of clinical outcomes. Stroke 2012; 43: 2362-8.

10. Shojima M, Nemoto S, Morita A, et al. Protected endovascular revascularization of subacute and chronic total occlusion of the internal carotid artery. AJNR Am J Neuroradiol 2010; 31: 481-6. 